\title{
The impact of advocacy and community mobilization on the utilization of health services at the Comprehensive Health Centre, Gindiri.
}

\author{
Dr Adah S.O*+, Ogbonna C*+, Anga P**, Chingle M.P*, Ashikeni M.A*, Envuladu E*, Agaba \\ C*, Audu S*, Bupwatda P*, Zoakah A.I*+ \\ *Department of Community Health, ** Dept of Family Medicine. Jos University Teaching hospital, P.M.B. 2084. Jos. \\ + Department of Community Health, University of Jos. \\ Correspondence to: Dr. Adah S, Department of Community Health, University of Jos P.M.B. 2084, Jos. Plateau State. Email- \\ adahsteve@yahoo.com
}

\begin{abstract}
Primary Health Care facilities provide promotive, preventive, curative and rehabilitative services to a community. They may be well built and equipped with adequate resources but grossly underutilized due to several factors.

Health records at the Comprehensive Health Centre Gindiri for 2005 were compared with those of 2007 after a wellcoordinated advocacy and mobilization programme in that community.

The results show that the total out patient attendance in 2007 increased by 220.6\% when compared to that of 2005.293 patients were admitted into the wards in 2005 compared to 813 in 2007(277\%). There was no surgery carried out in the whole of 2005 , whereas in 2007 there were 98 surgeries.

Advocacy and community mobilization could be important factors in the utilization of primary health services.
\end{abstract}

\section{Introduction}

Comprehensive Health centres are Primary Health Care facilities providing promotive, preventive, curative and rehabilitative services to a community. They may be well built and equipped with adequate resources human, material; and well funded with tax payers money, but grossly underutilized due to several factors that may be economic, educational, geographical, sociocultural, political, legal or religious. $1,2,3$ The attitude of health workers, availability of doctors, irregular supplies and commodities and inefficient service delivery are other strong factors affecting utilization of these health services.1,2,3 In Africa, up to $80 \%$ of the population uses traditional medicine for primary health care. ${ }^{4}$ Eighty-five per cent of Nigerians use and consult traditional medicine for healthcare, social and psychological benefits. ${ }^{5,6}$ In rural Burkina Faso, modern health care facilities are only consulted by $19 \%$ of the population; others choose home treatment $(52 \%)$, traditional healers $(17 \%)$, or local village health workers $(5 \%)$. This translates in a utilization of government services as low as 0.17 consultations per capita in 1997.3 In Ghana, Mali, Nigeria and Zambia, herbal medicines are the first line of treatment for 60 per cent of children with high fever from malaria. ${ }^{5}$ About $60-85$ per cent of births delivered in Nigeria and especially in the rural communities are by the Traditional Birth Attendants and these take place outside the Health facilities. ${ }^{6,10}$ Many patients prefer to seek care at the patent medicine stores or with the traditional medicine operators instead of the formal health sector. ${ }^{3}$

Community mobilization and participation are known to play a key role in utilization of health services, by ensuring ownership and sustainability of health programmes and interventions. It involves encouraging the community to take part in their health care and development. It is a lengthy process and not only implies that the community members, government and NGOs come together to develop a strategy to resolve issues within the community, but also entails the pooling of their resources. A key component of community mobilization involves identifying and developing leaders from the community by strengthening and building their capacities in various issues. Community mobilization is neither a campaign that is undertaken once, nor is it a series of campaigns carried out over a period of time. It is a continual and cumulative communication through educational and organizational processes that produces a growing autonomy and consciousness in the community about taking development into their hands. Such efforts need to be sustainable and sustainability of social change is more likely if the individuals and communities have a sense of ownership in the development process and that communities should be the agents of their own change. The communities should be mobilized to participate in their development or health activities from the planning to implementation, monitoring and evaluation phases to ensure ownership and sustainability. The establishment of health development committees is one way of ensuring community participation and could be used to mobilize the community.

The Comprehensive health Centre Gindiri, is one of the Rural Health centers established by the Jos university teaching Hospitals in 1988 and commissioned in April 1990 to provide comprehensive Primary health care to the people of Gindiri in Plateau state. The management of the Jos University teaching Hospital recently, in the year 2006 appointed a Community physician as the medical superintendent to oversee the management of the hospital. He was charged with the responsibility of improving the utilization of the hospital and its revenue base. One of the strategies adopted by the new management at the health centre was advocacy and the mobilization of the host communities from February 2006.

There were also efforts to improve staff strength and the motivation of the health workers through renovation of staff quarters and continuous medical development.

\section{Methods}

This is a retrospective study. Health records at the Comprehensive health centre Gindiri showing out patient attendance by adult males and females, and paediatric cases 


\begin{tabular}{lrr}
\hline Month & $\mathbf{2 0 0 5}$ & $\mathbf{2 0 0 7}$ \\
\hline January & 48 & 148 \\
February & 50 & 189 \\
March & 70 & 165 \\
April & 49 & 171 \\
May & 64 & 212 \\
June & 135 & 177 \\
July & 107 & 166 \\
August & 89 & 150 \\
September & 65 & 184 \\
October & 132 & 179 \\
November & 124 & 220 \\
December & 76 & 190 \\
\hline Total & 1009 & 2151 \\
\hline
\end{tabular}

Table 1: Monthly Adult Male Outpatient Attendance at Comprehensive Health Centre Gindiri in 2005 and 2007

\begin{tabular}{lll}
\hline & $\mathbf{2 0 0 5}$ & $\mathbf{2 0 0 7}$ \\
\hline Adult males & 1009 & 2151 \\
Adult females & 1284 & 3690 \\
Paediatric & 1325 & 2142 \\
\hline Total & 3618 & 7983 \\
\hline
\end{tabular}

Table 3: Total outpatient attendance at Comprehensive Health Centre Gindiri in 2005 and 2007

( $<15$ years old) in 2005 were compiled and summarised. These records were compared with those obtained in 2007 after a well coordinated advocacy and mobilization programme in the same community. The numbers of admissions during the same period were also examined

\section{Results and Discussion}

The results show that there were a total of 1,009 male outpatients in 2005. This increased to 2151 in 2007 (Table 1). A total of 1,284 female outpatients were seen in 2005 and this had increased by $287 \%$ in 2007 (Table 2). With regards to paediatric outpatients, 1,325 patients were seen in 2005, however by 2007, 2142 cases or an increase of $161 \%$ was recorded (Table 3). By 2007 the total outpatient attendance had increased by $220.6 \%$ compared to the attendance in 2005. 293 patients were admitted into the wards in 2005 compared to 813 in 2007 (Figure 1). Records also showed that there was no surgery carried out in the whole of 2005 , whereas in 2007 there were 98 surgeries. These improvements in the utilization of services at the Comprehensive Health Centre, Gindiri followed the intensive and organized continuous community mobilization and advocacy commenced February 2006.

\section{Conclusion}

This study shows that Advocacy and community mobilization could be important factors in the utilization of primary health services, especially in combination with

\begin{tabular}{lrr}
\hline Month & $\mathbf{2 0 0 5}$ & $\mathbf{2 0 0 7}$ \\
\hline January & 60 & 303 \\
February & 80 & 305 \\
March & 100 & 325 \\
April & 71 & 276 \\
May & 97 & 431 \\
June & 150 & 299 \\
July & 169 & 333 \\
August & 140 & 260 \\
September & 105 & 280 \\
October & 129 & 271 \\
November & 88 & 325 \\
December & 95 & 282 \\
\hline Total & 1284 & 3690 \\
\hline
\end{tabular}

Table 2: Monthly Adult Female Outpatient Attendance at Comprehensive Health Centre Gindiri in 2005 and 2007

other efforts to strengthen manpower and service delivery. These factors may have confounded this study.

We strongly recommend that health managers should engage in active, purposeful and continuous advocacy and mobilization of the community so as to promote ownership and sustainable improvement in the utilization of health services. This will complement other efforts such as manpower capacity development, infrastructural development, attitudinal reorientation and provision of essential drugs and commodities, directed at improving efficiency and efficacy of the health system.

Further controlled or experimental studies may reduce the confounders in this study.

\section{References}

1. Adetokunbo O. Lucas and Herbert M. Gilles. Short textbook of public Health Medicine for the Tropics. Bookpower. 4th edition.2003.pp4,283-287

2. Slim Haddad, Fournier P. Quality, cost and utilization of health services in developing countries_ A longitudinal study in Zaïre.htm.infoclient@ inist.fr

3. Baltussen Rob and Yazoume Ye Quality of care of modern health services as perceived by users and non-users in Burkina Faso. International Journal for Quality in Health Care 2005: $18(1) ; 30-34$

4. Traditional medicine - Wikipedia, the free encyclopedia.htm

5. Science and Development Network. Traditional Medicine. www.google.com

6. Traditional Medical Care in Nigeria OnlineNigeria_com.htm Accessed May 14, 2008

7. Fosu GB. Childhood morbidity and health services utilization: cross-national comparisons of user-related factors from DHS data. Soc Science Med: 38 (9); 1209-20.

8. Diop FP, Economic determinants of child health and the utilization of health services in Sub-Saharan Africa the case of Ivory Coast. Ann Arbor, Michigan, University Microfilms International, 1990. vii, 213 p. (Order No. 9030184)

9. Buor D. Analyzing the Primacy of distance in the utilization of Health services in the Ahafo-Ano South District of Ghana. The International Journal of Health Planning and Management 2003: 18(4);293-311.

10. Okonkwo JEN, Ngene JN. Determinants of Poor Utilization of Orthodox Health Facilities in a Nigerian Rural Community. Nigerian Journal of Clinical Practice 2004: 7(2); 74-78.

11. Christipher N Obionu. Primary Health Care for developing Countries. Ezu Books 1td. 2nd edition.2007.pp1-24.

12. Omotara BA, Yahya SJ, Shehu U, Bello HS, Bassi AP. Communities' Awareness, Perception and Participation in the Community-Based Medical Education of the University of 
Maiduguri. Education for Health, 2006. 19(2) 147-54

13. Benjamin S.C. Uzochukwu, Obinna E. Onwujekwe, Cyril O. Akpala. Did the Bamako Initiative Improve the Utilization of Maternal and Child Health-Care Services in Nigeria? A Case Study of Oji River Local Government Area in Southeast Nigeria. World health and population in developing countries. 2004.
14. Stock R. Distance and the utilization of health facilities in rural Nigeria. Soc Sci Med 1983;17(9):563-70

15. Ebuehi OM, Roberts AA Inem V. Determinants of Utilization of Maternal Health Services Among Traders in Lagos Markets. Nigerian Quarterly Journal of Hospital Medicine 2006; 16(2) 